\title{
Commentary: When will we learn from using donor hearts with decreased ventricular function?
}

\author{
Stephen H. McKellar, MD, MSc \\ From the Division of Cardiothoracic Surgery, Department of Surgery, University of Utah School of Medicine, Salt \\ Lake City, Utah. \\ Disclosures: Author has nothing to disclose with regard to commercial support. \\ Received for publication Aug 6, 2018; accepted for publication Aug 10, 2018; available ahead of print Sept 20, \\ 2018. \\ Address for reprints: Stephen H. McKellar, MD, MSc, 30 N 1900 E, Suite 3C, 127 SOM, Salt Lake City, UT 84132 \\ (E-mail: stephen.mckellar@hsc.utah.edu). \\ J Thorac Cardiovasc Surg 2019;157:1876-7 \\ $0022-5223 / \$ 36.00$ \\ Copyright $(2) 2018$ by The American Association for Thoracic Surgery \\ https://doi.org/10.1016/j.jtcvs.2018.08.027
}

I congratulate Sibona and coauthors ${ }^{1}$ for their article in this issue of the Journal, "Long-term Transplant Outcomes of Donor Hearts with Left Ventricular Dysfunction." In this article, they queried the United Network for Organ Sharing Standard Transplant Analysis and Research data set to study the question of clinical outcomes in transplanting hearts with decreased left ventricular (LV) function. They compared clinical outcomes of recipients of donor hearts with decreased LV ejection fraction (LVEF) with those of recipients of normal donor hearts. The donors of hearts with decreased LV function were more likely to be male, to be younger, to have died of head trauma, and to have smaller body mass index, and recipients were more ill, as manifested by their being more likely to be mechanically ventilated and receiving inotropes at the time of transplant. Sibona and coauthors ${ }^{1}$ observed no difference in survival among their $3 \mathrm{LV}$ function groups during follow-up extending across 15 years, with a median follow-up of $5.1 \pm 4.3$ years. LVEF did not predict mortality, and LVEF normalized with time. Sibona and coauthors ${ }^{1}$ conclude that carefully selected donors with low LVEF can be used with equivalent outcomes. They argue that LV dysfunction alone should not be the reason donor hearts are rejected.

These results are encouraging for those interested in expanding the availability of heart transplantation. One would expect that the use of marginal hearts would lead to more acute mechanical circulatory support such as extracorporeal membrane oxygenation, but that was not the case.

So, what can we conclude from these data? Expert clinicians have made good decisions for the past 16 years regarding which low-LVEF hearts could be used. It appears that the practice was to use hearts from young, white, thin, men whose cause of death was either anoxia or head trauma. Perhaps clinicians assumed that these were the most resilient organs. It also appears that these hearts performed granular data. forward.

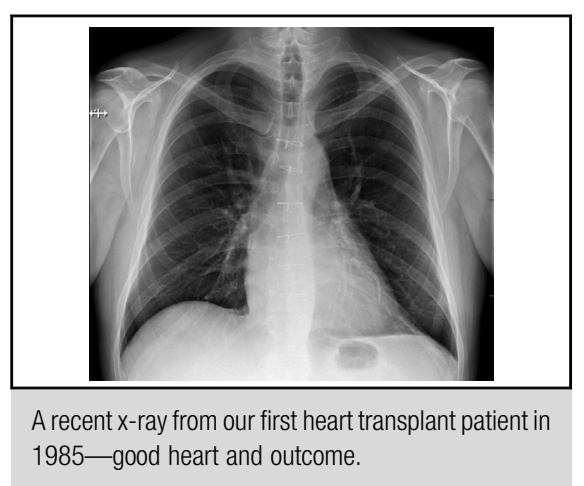

\section{Central Message}

This article reports equivalent outcomes from transplanting hearts with decreased ventricular function, raising the question of whether more marginal hearts should be used.

See Article page 1865.

well, as evidenced by equivalent outcomes despite sicker recipients. Whether the clinicians' assumptions were correct is unknown, however, and will remain so with retrospective observational data. Only randomized trials can provide such

The progress toward the use of more marginal donor hearts will likely end, however, with well-designed retrospective studies like this one. If a transplant program's vital metric is Scientific Registry of Transplant Recipients outcomes data, how can clinicians take calculated risks to study LV dysfunction if the risks ultimately shutter the program? How will the field really evolve if learning ultimately proves fatal to the transplant program's survival? The current stringent, risk-averse regulatory environment is hampering learning and innovation regarding the use of marginal hearts. Only well-designed human clinical trials will answer the questions needed to move the field

This could be done if the Scientific Registry of Transplant Recipients outcomes were to be modified to parallel the risk categorization already built into the system of solid organ transplantation, the US Public Health Service increasedrisk organs. Currently, when a Public Health Service highrisk organ is offered, the patient has the opportunity to accept or reject the risk of infectious disease transmission without penalty. Similarly, marginal hearts could be studied 
as patients and centers participate in in prospective clinical trials in which such hearts are offered to both patients and centers without penalty.

\section{Reference}

1. Sibona A, Khush KK, Oyoyo UE, Martens TP, Hasaniya NW, Razzouk AJ, et al Long-term transplant outcomes of donor hearts with left ventricular dysfunction. $J$ Thorac and Cardiovasc Surg. 2019;157:1865-75. 